\title{
Tensions and strengths in the research on Mathematics Teacher Education and Mathematics Teacher practices
}

\author{
Salvador Llinares ${ }^{1}$
}

Accepted: 8 November 2021 / Published online: 10 November 2021

(c) The Author(s), under exclusive licence to Springer Nature B.V. 2021

The research on Mathematics Teaching and Mathematics Teacher Education displays different tensions and strengths. One of the tensions comes from the relation between general and subject-specific approaches (Herbst \& Chazan, 2016) when the research questions are formulated. It is also possible to identify strengths regarding the analytical approaches adopted to produce new knowledge integrating it in findings from previous studies as a feature of the research in the field of social science research. The articles in this issue display how researchers manage these features to study different aspects of Mathematics Teacher Education and Mathematics teacher practices. These tensions and strengths influence the theory, the instruments for data collection and the analytical approach adopted (which categories and how they are generated) to produce new knowledge. Although these tensions and strengths are present in the articles in this issue of JMTE, we can also identify them when we look back at previous issues of JMTE.

We should understand the tensions between general and subject-specific approaches and the ways in which we generate new knowledge as features of the research about Mathematics Teacher Education and Mathematics Teacher practices developed in the last decades. In this research field, how the researchers produce new knowledge and the role of Mathematics and how they decide to study are linked, showing clearly different characteristics of these study fields.

The strengths of the studies are reflected when the newly generated knowledge can be integrated in findings from previous studies using, adapting and extending analytical codes from other studies. This feature is evidenced when the researchers start using codes and categories in their analysis from previous studies and adapt, or modify them to answer questions about a similar educational problem. In this issue of JMTE, Wæge and Fauskange use codes from other studies on rehearsals, although additional codes emerged from their data and revealed the role of scaffolds ("Teacher time outs", TTOs) in supporting inservice teachers' learning. Furthermore, Oi-Lam Ng, Wing Kin Cheng, Yujing Ni and Lian Shi examine how teachers' discourse influences patterns of authority in the mathematics classroom using coding schemes to analyze talk moves from previous studies, but adding new codes to reflect specific cultural practice of mathematics teaching in this case from China. So, the practice of using initial codes from previous studies and then adapting them

Salvador Llinares

sllinares@ua.es

1 University of Alicante, Alicante, Spain 
and adding new ones to better understand the studied phenomenon may be considered a nuance of these studies.

The tensions between subject-specific and general approaches are shown in the different articles indicating its necessary complementarity. For example, the research focus on how students' mathematical thinking is considered in educational products or to develop a teachers' response move, help to the researchers to make mathematical knowledge visible. For example, in the study by Douglas L. Corey, Steven Williams, Eula E. Monroe and Michelle Wagner, they focused on how student's mathematical thinking was considered in the educational products. In particular, on what mathematics student know or do not know (student mathematical knowledge) or on how students reason through problems (students mathematical reasoning). This approach allows the authors to characterize how the students mathematical thinking is shown in the Written Instructional Products: how it was specified, varied and detailed. In the same way, the study by Andrew M. Tyminski, Amber J. Simpson, Tonia J. Land, Corey drake and Ercan Dede focused on the influence of noticing students' mathematical thinking on the teacher' capacity to promote some specific response move in teaching. In particular, using analytical codes linking teachers' instructional moves to the description and interpretation of students' mathematical thinking. While in Wæge and J. Fauskanger's study, the categories of teachers' practice addressed in the TTOs during the rehearsals (such as using representations, aiming toward goals, launching problems, facilitating student talk and organizing the board) attempt to show how the management of mathematical content in instruction was considered. On the other hand, Oi-Lam Ng and colleagues' study is focused on characterizing ways in which dialogic discourse may influence how authority is structured in the mathematics classroom. In this case, the authority structures were identified by linguistics clues in which the mathematical content was inserted.

The way in which researchers manage the relation between subject-specific and general approaches and the use of analytical codes from other studies shows relevant characteristics of Mathematics Teacher Education and Mathematics Teacher practice. In the articles in this issue of JMTE, these tensions and strengths lead to the identification of two of these characteristics. Firstly, considering the relevance of cultural differences, and, secondly, taking into account the role of different types of scaffolding to support teachers' learning.

The relevance of cultural differences can be identified in the studies by D.L. Corey and colleagues and Oi-Lam Ng and colleagues in this issue of JMTE. For example, when D.L. Corey and colleagues study how knowledge of students' mathematical thinking appears in the instructional products from the USA and Japan and how this knowledge is used to guide and justify instructional decisions, or when Oi-Lam $\mathrm{Ng}$ and colleagues adapted codes and categories of analysis from a different cultural context (China and Western-culture) to study how linguistic features and patterns of discourse moves influence authority structures in the mathematics classroom. Corey and colleagues narrow their focus on the attention paid by teachers to students' thinking during a lesson trying to contribute to understanding the development of a knowledge base for teaching. They use published articles from practitioner journals as Written Instructional Products (WIPs) to characterize how teachers take into account the students' thinking during a lesson. How students' mathematical thinking is illustrated in instructional products from the USA and Japan and underline cultural differences providing new knowledge in our attempts to understand to what extent the ways of sharing teachers' knowledge can help to build a knowledge base for instruction. Oi-Lam $\mathrm{Ng}$ and colleagues' article underlines the relevance of how authority is structured across different languages looking at the variation in the teachers' discourse moves (using a case study). In this case, the relation between ways of discourse and authority patterns takes into 
consideration the influence of cultural heritage in the nature of interaction between teachers and student. Using codes such as revoice, press for reasoning, say more, ask for expression and request collective responses allows the authors to establish some type of relationships between the teacher' discourse patterns and the authority structures generated in the classroom. The nature of these relationships is contextualized from a cultural perspective.

A second aspect is the role played by some type of scaffolding in supporting teacher's learning. For example, regarding the role played by a specific reading as a scaffold to support how preservice teachers use their interpretations of students' mathematical thinking to develop responses which extend the student' thinking in the study by Tyminski and colleagues; or the use of teacher time out (TTOs) by Wæge and J. Fauskanger when some core practices are rehearsed as part of cycles of enactment and investigation to support in-service teachers' learning. Although the studies by Tyminski and colleagues and Wæge and Fauskange have different aims, developing preservice teachers' responses which extend the student's thinking and support learning to enact the practices that constitute ambitious mathematics teaching, both studies focus their attention on the role played by some type of scaffold to support the prospective and in-service teachers' learning. Wæge and Fauskange's article analyzes how the pauses (TTOs) in the rehearsal of moves that are responsive to the students contributions help teachers to discuss teaching strategies within cycles of enactment and investigation for professional development, while Tyminski and colleagues' article focuses its attention on the role played by a reading (information for preservice teacher) to support the prospective teachers' responses to extend students' mathematical thinking.

The four articles in this issue can be situated in different places considering the tensions between general and subject-specific approaches and the way in which analytical approaches are used from previous studies (in particular the use of previous code system) to generate new knowledge. However, these studies provided new knowledge and perspectives in conceptual and methodological dimensions making us more aware of the cultural differences in mathematics teaching practice, and of the role played by different scaffolds in supporting prospective teacher' learning in Mathematics Teacher Education.

\section{Reference}

Herbst, P., \& Chazan, D. (2016). The role of theory development in increasing the subject specificity or research on mathematics teaching. In J. Cai (Ed.), Compedium for research in mathematics education (pp. 102-127). Reston, VA: NCTM.

Publisher's Note Springer Nature remains neutral with regard to jurisdictional claims in published maps and institutional affiliations. 